\title{
Site-Selective Passivation of Defects in NiO Solar Photocathodes by Targeted Atomic Deposition
}

\author{
Cory J. Flynn, ${ }^{\dagger}$ Shannon M. McCullough, ${ }^{\dagger}$ EunBi Oh, $^{\dagger}$ Lesheng Li, $^{\dagger}$ Candy C. Mercado, ${ }^{\dagger}$ \\ Byron H. Farnum, ${ }^{\dagger}$ Wentao Li, ${ }^{\dagger}$ Carrie L. Donley, ${ }^{\S}$ Wei You, ${ }^{\dagger}$ Arthur J. Nozik, ${ }^{\ddagger}, \|$ James R. McBride, ${ }^{\perp}$ \\ Thomas J. Meyer, ${ }^{\dagger}$ Yosuke Kanai, ${ }^{\dagger}$ and James F. Cahoon ${ }^{* \dagger}$ \\ ${ }^{\dagger}$ Department of Chemistry, University of North Carolina at Chapel Hill, Chapel Hill, North Carolina 27599-3290, United States \\ ${ }^{\ddagger}$ Renewable and Sustainable Energy Institute and Department of Chemistry and Biochemistry, University of Colorado, Boulder, \\ Colorado 80309-0027, United States \\ ${ }^{\S}$ Chapel Hill Analytical and Nanofabrication Laboratory (CHANL), Department of Applied Physical Sciences, University of North \\ Carolina at Chapel Hill, Chapel Hill, North Carolina 27599-3216, United States \\ "National Renewable Energy Laboratory, 15013 Denver West Parkway, Golden, Colorado 80401, United States \\ ${ }^{\perp}$ Vanderbilt Institute of Nanoscale Science and Engineering, Vanderbilt University, Nashville, Tennessee 37235, United States
}

\begin{abstract}
For nanomaterials, surface chemistry can dictate fundamental material properties, including charge-carrier lifetimes, doping levels, and electrical mobilities. In devices, surface defects are usually the key limiting factor for performance, particularly in solarenergy applications. Here, we develop a strategy to uniformly and selectively passivate defect sites in semiconductor nanomaterials using a vapor-phase process termed targeted atomic deposition (TAD). Because defects often consist of atomic vacancies and dangling bonds with heightened reactivity, we observe-for the widely used p-type cathode nickel oxide-that a volatile precursor such as trimethylaluminum can undergo a kinetically limited selective reaction with these sites. The $\mathrm{TAD}$ process eliminates all measurable defects in $\mathrm{NiO}$, leading to a nearly 3 -fold improvement in the performance of dye-sensitized solar cells. Our results suggest that $\mathrm{TAD}$ could be implemented with a range of vapor-phase precursors and be developed into a general strategy to passivate defects in zero-, one-, and two-dimensional nanomaterials.
\end{abstract}

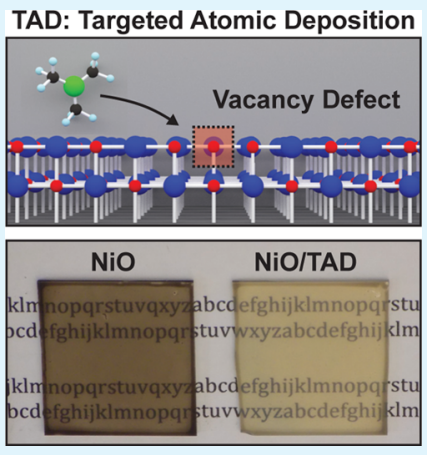

KEYWORDS: nickel oxide, dye-sensitized solar cell, atomic layer deposition, DFT+U calculations, p-type metal oxide

\section{INTRODUCTION}

Semiconductor nanomaterials, including zero-dimensional (OD) nanocrystals, one-dimensional (1D) nanowires, and two-dimensional (2D) nanosheets, have received widespread attention for their unique physical properties, which lead to applications in catalysis, ${ }^{1}$ energy harvesting, ${ }^{2}$ energy storage, ${ }^{3}$ and sensing, ${ }^{4}$ among others. The high surface-to-volume ratios and interfacial areas cause the surface to strongly influence the properties of both single particles and assembled materials. For instance, capping ligands on $0 \mathrm{D}$ quantum $\operatorname{dots}^{5}$ (QDs) are regularly used to improve the electrical mobility ${ }^{6}$ and photovoltaic device performance ${ }^{7,8}$ of $\mathrm{QD}$ devices. In $1 \mathrm{D}$ nanowires, passivating wide-band-gap shells are often grown to reduce surface recombination. ${ }^{9}$ For $2 \mathrm{D}$ materials such as graphene and $\mathrm{MoS}_{2}$, the doping level, mobility, and chargecarrier lifetime are known to be strongly dependent on singlesite and line defects. ${ }^{10-12}$ General strategies to passivate defects in these materials are needed to realize their potential in solar energy applications. ${ }^{13}$

Here, we characterize a process termed targeted atomic deposition (TAD) for the passivation of defects in the commonplace but often problematic material nickel oxide (NiO). A wide-band-gap p-type semiconductor, $\mathrm{NiO}$ is used as a hole-transport and electron-blocking layer in energy-related devices, including electrochromic windows, ${ }^{14}$ batteries, ${ }^{15}$ electrocatalytic water-splitting systems, ${ }^{16}$ organic photovoltaics, ${ }^{17}$ organohalide perovskites, ${ }^{18}$ and p-type dye-sensitized solar cells (DSSCs). ${ }^{19-21}$ Depending on the application, $\mathrm{NiO}$ is used as a dense thin film or as nanoparticles or nanoplatelets ${ }^{19}$ assembled into a mesoporous structure. It is well-known to have a high density of nickel $(\mathrm{Ni})$ vacancies, ${ }^{17,22}$ giving rise to the p-type doping, gray-to-black color, and electrochromic behavior of the material. ${ }^{23,24}$ In DSSC devices, NiO typically produces power conversion efficiencies several times lower than those of analogous devices using $\mathrm{TiO}_{2}{ }^{25}$ The low performance is attributable to a high defect density ${ }^{25}$ and low electrical mobility, which lead to high rates of surface-mediated recombination. ${ }^{25,26}$ Previous work to improve $\mathrm{NiO}$ has shown

Received: January 26, 2016

Accepted: January 28, 2016

Published: January 28, 2016 
only moderate success, including increased mobility through morphology, ${ }^{19}$ reduced recombination from higher crystallinity, ${ }^{27,28}$ overlayers from atomic layer deposition (ALD) ${ }^{29}$ or solution-phase deposition, ${ }^{30}$ and lithium doping to fill trap states. $^{23}$ However, defects still consistently limit the performance of the material. ${ }^{25}$

We used $\mathrm{TAD}$ to passivate defect sites in $\mathrm{NiO}$ by taking advantage of a kinetically limited, vapor-phase reaction in which the most reactive sites on the material's surface-the defect sites-are selectively passivated with aluminum (Al). Highly reactive oxygen $(\mathrm{O})$ dangling bonds adjacent to $\mathrm{Ni}$ vacancies selectively react with trimethylaluminum (TMA), as shown in Figure $1 \mathrm{a}$, and the passivation of these sites results in a nearly 3-
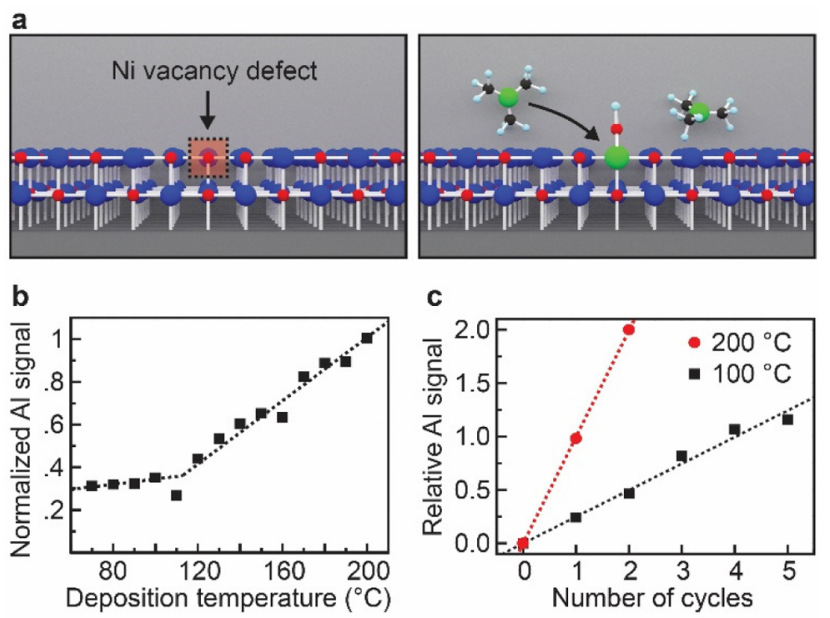

d

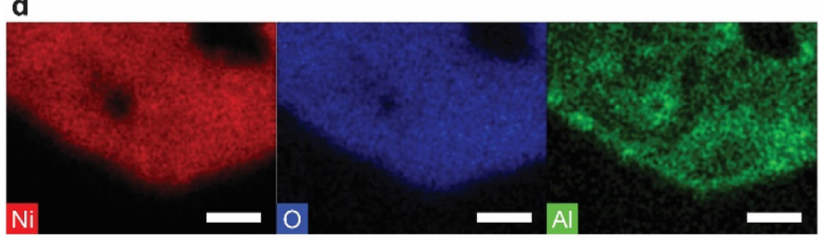

Figure 1. Selective vapor-phase deposition of $\mathrm{Al}$ on $\mathrm{NiO}$. (a) Left: Schematic representation of a single $\mathrm{Ni}$ vacancy on the $\mathrm{NiO}$ surface. Right: Schematic representation of the TAD process, yielding siteselective passivation of the vacancy defect through a kinetically controlled reaction with TMA, forming $\mathrm{Al}(\mathrm{OH})_{x}$. Images depict $\mathrm{Ni}$ (blue), $\mathrm{O}$ (red), $\mathrm{Al}$ (green), $\mathrm{C}$ (black), and $\mathrm{H}$ (gray) atoms. (b) Normalized $\mathrm{Al}$ content, determined by the XPS $\mathrm{Al} / \mathrm{Ni}$ weight percent ratio, as a function of the deposition temperature for a single deposition cycle on nanoplatelet $\mathrm{NiO}$ films (black squares). Dashed lines represent separate linear fits to data above and below $120^{\circ} \mathrm{C}$. (c) Relative $\mathrm{Al}$ content for $\mathrm{ALD}$ (red circles) and for TAD (black squares) as a function of the number of deposition cycles. All values are relative to the signal from one $200{ }^{\circ} \mathrm{C}$ cycle, and dashed lines represent linear fits to the data. (d) EDS STEM mapping of an ultrathin porous $\mathrm{NiO}$ nanoplatelet showing maps of $\mathrm{Ni}$ (red), $\mathrm{O}$ (blue), and $\mathrm{Al}$ (green) following two cycles of TAD. All scale bars: $8 \mathrm{~nm}$.

fold improvement in the performance of DSSC devices. The results suggest that TAD could be developed into a universal strategy to passivate defects in $0 \mathrm{D}, 1 \mathrm{D}$, and $2 \mathrm{D}^{12}$ nanomaterials by exploiting the selective reactivity of defects with high-energy, vapor-phase precursors.

Additive vapor-phase deposition processes, including chemical vapor deposition, molecular beam epitaxy, and ALD, are regularly used in the fabrication of high-performance semiconductor devices. These processes are designed for layered or thin-film deposition of materials on a broad range of substrates. $\mathrm{TAD}$ is a complementary vapor-phase process optimized for site-selective modification of substrates rather than additive deposition, yielding a chemically passivated material. In technical implementation, TAD is similar to ALD in that both techniques can be performed in a low-pressure, temperature-controlled chamber by introducing alternating doses of two precursors. In an ALD process, all thermodynamically favored reactions react to completion with a vapor-phase precursor at the sterically accessible sites on a material's surface, $^{31}$ and tens to hundreds of dosage cycles are used to build up nanometer-thick films. ${ }^{32-34}$ In contrast, TAD, as shown below, is a kinetically limited, ${ }^{35}$ rather than a thermodynamically limited, process performed with a small number of dosage cycles at a temperature below the ALD process window, typically $150-200{ }^{\circ} \mathrm{C}$ for the precursors TMA and water. ${ }^{31}$ TAD takes advantage of temperature-dependent chemistry that can occur within the first or second kinetically limited deposition cycles.

\section{MATERIALS AND METHODS}

NiO Paste Preparation. $\mathrm{Ni}(\mathrm{OH})_{2}$ nanoplatelets, prepared by literature methods, ${ }^{19}$ were calcined in air $\left(350{ }^{\circ} \mathrm{C}\right.$; 40 min; humidity $<20 \%$ ), and a paste was prepared by first mixing $\mathrm{NiO}$ (16 g), $\alpha$ terpineol $(64.9 \mathrm{~g})$, ethanol $(63.1 \mathrm{~g})$, and ethyl cellulose [a $45 \mathrm{~g}(10 \mathrm{wt}$ $\%$ in ethanol) $5-15 \mathrm{mPa} \cdot \mathrm{s}$ solution combined with a $35 \mathrm{~g}(10 \mathrm{wt} \%$ in ethanol), 30-50 $\mathrm{mPa} \cdot \mathrm{s}$ solution] and second homogenizing by horn sonication, mechanical dispersing, and ball milling. ${ }^{36}$ Pastes of spherical $\mathrm{NiO}$ nanoparticles (Inframat Advanced Materials) were prepared following the same paste procedures.

NiO Film Preparation. A mesoporous layer of $\mathrm{NiO}(\sim 1.6 \mu \mathrm{m}$ thickness) was deposited onto fluorine-doped tin oxide (FTO; Hartford Glass, TEC15) substrates by spin-casting (Laurell WS$650 \mathrm{MZ}-23 \mathrm{NPP} ; 5 \mathrm{~s}$ at $500 \mathrm{rpm}$ and $30 \mathrm{~s}$ at $1500 \mathrm{rpm}$ ) and annealing in air $\left(450{ }^{\circ} \mathrm{C} ; 40 \mathrm{~min}\right.$; humidity $\left.<20 \%\right)$. The active area was then defined by mechanically removing excess material. $\mathrm{Al}$ deposition was performed in an Ultratech Savannah S200 system using TMA and water. TAD was performed at $100{ }^{\circ} \mathrm{C}(10 \mathrm{~ms}$ precursor pulses; $10 \mathrm{~s}$ hold; $60 \mathrm{~s}$ purge), whereas ALD was performed at $200{ }^{\circ} \mathrm{C}(20 \mathrm{~ms}$ precursor pulses; $20 \mathrm{~s}$ hold; $60 \mathrm{~s}$ purge). A portion of these substrates were annealed in air $\left(450{ }^{\circ} \mathrm{C}\right.$; $40 \mathrm{~min}$; humidity <20\%). All temperature-dependent data sets (e.g., Figures $1 b, c$ and and S3c) were collected with $10 \mathrm{~ms}$ precursor pulses. See Tables S8 and S9 for deposition details.

Computational Analysis. First-principles calculations on the $\mathrm{NiO}$ surface using density functional theory (DFT) with the Hubbard correction follow the same approach as that in ref 37 . A periodically repeating and symmetric slab (76-atom cell; $24.10 \AA$ thickness; $15 \AA$ vacuum region normal to the surface) is used to model the $\mathrm{NiO}$ (111) surface with octopolar reconstruction. The $\mathrm{Ni}$ vacancy and $\mathrm{Al}$ doping were modeled by removing or substituting one $\mathrm{Ni}$ atom with an $\mathrm{Al}$ atom in the topmost stoichiometric layer. See the Supporting Information (SI) for computational details.

Solar-Cell Fabrication. The electrode films were immersed in a P1 solution ( $0.3 \mathrm{mM}$ in acetonitrile) overnight, rinsed with acetonitrile, and dried with $\mathrm{N}_{2}$. Platinum $(\mathrm{Pt})$ counter electrodes were fabricated by thermal decomposition $\left(380{ }^{\circ} \mathrm{C}\right.$; $30 \mathrm{~min}$; humidity $<20 \%$ ) of chloroplatinic acid (5 mM in 2-propanol) on FTO glass with a predrilled hole. The counter electrode was sandwiched with the working electrode using a $25 \mu \mathrm{m}$ Surlyn gasket in a custom-made heat press $\left(150{ }^{\circ} \mathrm{C} ; 10 \mathrm{~s}\right)$. The hole was sealed with Surlyn $\left(150^{\circ} \mathrm{C} ; 5 \mathrm{~s}\right)$. A Z960-like electrolyte (1.0 M 1,3-dimethylimidazolium iodide, iodide $(0.03 \mathrm{M})$, tert-butylpyridine $(0.5 \mathrm{M})$, and guanidium thiocynanate $(0.1$ M) in 85:15 (v/v) acetonitrile/valeronitrile] was vacuum-backfilled. The cell was then sealed $\left(150{ }^{\circ} \mathrm{C}, 5 \mathrm{~s}\right)$ with a Surlyn film and a microscope coverslip. The active area of each electrode was $\sim 0.7 \mathrm{~cm}^{2}$. 
Characterization. Absorption measurements were performed on an Agilent Cary 5000 spectrometer with an integrating sphere. Elemental quantification was performed by X-ray photoelectron microscopy (XPS) with a Kratos Axis Ultra DLD spectrometer. All XPS data were corrected to the $\mathrm{C} 1 \mathrm{~s}$ peak $(284.6 \mathrm{eV})$ and backgroundcorrected. Because of varying experimental intensities, the $\mathrm{Al}$ content is reported as the ratio of the $\mathrm{Al} / \mathrm{Ni}$ wt \%. Elemental quantification was also performed by energy-dispersive X-ray spectroscopy (EDS) on a FEI Helios 600 scanning electron microscope. High-resolution EDS mapping was obtained with an FEI Tecnai Osiris scanning transmission electron microscope equipped with a Super-X EDS system. Drift-corrected scanning transmission electron microscopy (STEM)-EDS maps were obtained using the Bruker Espirit software with a spatial resolution of $\sim 0.5 \mathrm{~nm}$. Spectroelectrochemistry $(50 \mathrm{mV}$ steps; $60 \mathrm{~s}$ holds) and cyclic voltammetry $\left(20 \mathrm{mV} \cdot \mathrm{s}^{-1}\right)$ were performed on a potentiostat $(\mathrm{CH}$ instruments $601 \mathrm{~d})$ in acetonitrile with lithium perchlorate $(0.1 \mathrm{M})$ in a three-electrode configuration (working, $\mathrm{FTO} / \mathrm{NiO} /$ treatment; counter, platinum wire; reference, $\mathrm{Ag} / \mathrm{AgCl}$ ). $J-V$ curves were obtained under back-illumination using a Newport Oriel 150W class ABB AM1.5G solar simulator calibrated to 1-sun intensity with a certified reference solar cell (Newport $91150 \mathrm{~V}$ ) using a Keithley 2636A sourcemeter (resolution, $1 \mathrm{mV}$; measure delay, 0.1 s). Incident photon-to-current efficiency (IPCE) measurements were obtained by illuminating devices with a tungsten lamp (Newport Instruments) coupled to a spectrometer (Princeton Instruments SP2300). Device carrier lifetimes were obtained from $V_{\mathrm{OC}}$ decays (sampling rate, $1 \mathrm{kHz}$ ) with a starting illumination of 1 sun and a shutter response of $<1 \mathrm{~s}$.

\section{RESULTS AND DISCUSSION}

Characterizing TAD of Al. We performed a TAD of alumina, using dosages of TMA and water, on ultrathin hexagonal nanoplatelets of $\mathrm{NiO}^{19}$ To determine the best conditions for $\mathrm{TAD}$, we first quantified the extent of $\mathrm{Al}$ deposition after one dosage cycle for temperatures ranging from 70 to $200{ }^{\circ} \mathrm{C}$ using XPS. As shown in Figure $1 \mathrm{~b}$, the $\mathrm{Al}$ content increases linearly for temperatures above $120^{\circ} \mathrm{C}$ but is approximately constant at lower temperatures. At all temperatures, the estimated deposition is less than one monolayer. The absence of a high-temperature plateau, which would be characteristic of a self-limited ALD process, ${ }^{31}$ combined with the submonolayer deposition suggests that the chemical processes occurring in the first cycle are kinetically limited and qualitatively different from the chemistry in subsequent cycles. In addition, the presence of a plateau below $120{ }^{\circ} \mathrm{C}$ suggests a unique chemistry in this low-temperature regime.

We selected $100{ }^{\circ} \mathrm{C}$ for further development of the TAD process and compared the results to deposition at $200{ }^{\circ} \mathrm{C}$, a typical temperature for ALD of aluminum oxide $\left(\mathrm{AlO}_{x}\right)$. As shown in Figure 1c for one to five cycles on $\mathrm{NiO}$, the $\mathrm{Al}$ content at $100{ }^{\circ} \mathrm{C}$ is $\sim 25 \%$ of the deposition at $200{ }^{\circ} \mathrm{C}$, which was separately confirmed by analysis with EDS (Tables S1 and S2) and SEM. In addition, the spatial uniformity of two cycles at $100{ }^{\circ} \mathrm{C}$ on nanoplatelet $\mathrm{NiO}$ was examined by EDS elemental mapping of $\mathrm{Ni}, \mathrm{O}$, and $\mathrm{Al}$ by STEM, as displayed in Figure 1d. The Al map shows uniform deposition across the particle with a subtle preference for the edges and pores of the platelets, which is confirmed by EDS line scans (Figure S1). EDS mapping after deposition at $200{ }^{\circ} \mathrm{C}$ showed similar behavior but substantially more Al (Figure S2). In addition, temperature-dependent XPS spectra (Figures S3 and S4) suggest that the chemical nature of the $\mathrm{Al}$ species deposited at $100{ }^{\circ} \mathrm{C}$ is qualitatively different from that of the species at 200 ${ }^{\circ} \mathrm{C}$, and the results indicate a preference to form aluminum hydroxide $\left[\mathrm{Al}(\mathrm{OH})_{x}\right]$ bonded to $\mathrm{Ni}$ at lower temperatures and
$\mathrm{AlO}_{x}$ bonded to $\mathrm{Al}$ at higher temperatures (see the SI for an extended discussion).

Passivation of Optical and Electronic Defect States. Following a single cycle of $\mathrm{TAD}$, the $\mathrm{NiO}$ samples were markedly bleached, as shown by the dramatic change from dark gray to off-white in Figure 2a. ${ }^{14,38}$ The absorbance of $\mathrm{NiO}$ films was examined as a function of the number of TAD cycles, as shown in Figure 2b. The bleaching of the film is apparent from the difference spectra (see the inset), which show two bleach features. We separately performed spectroelectrochemical measurements on untreated $\mathrm{NiO}$ (Figure S5), and the data show spectral features similar to those of the TAD-treated NiO.
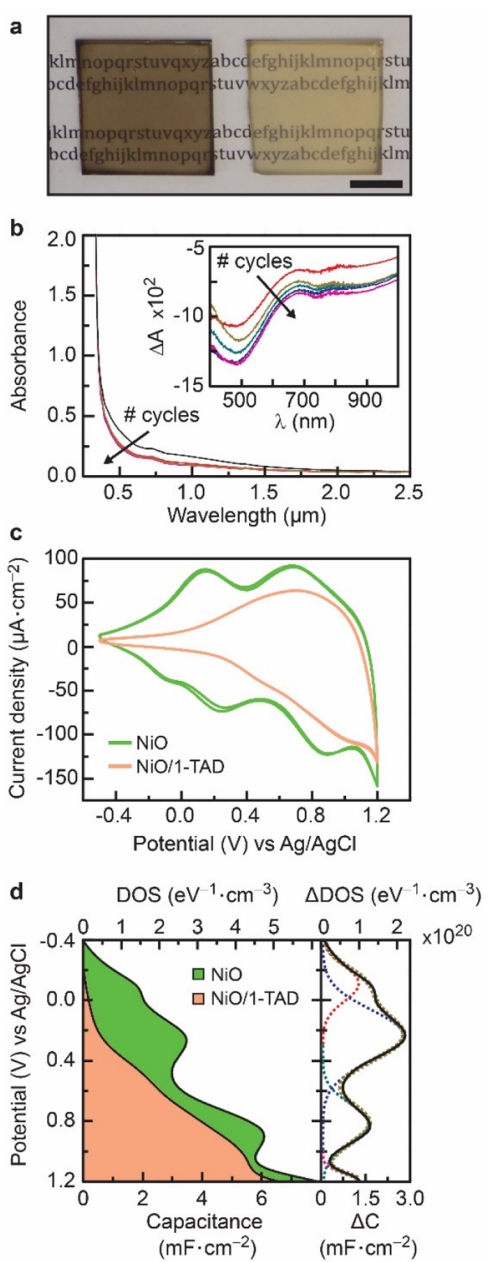

Figure 2. Optical and electronic effects of defect passivation: (a) Optical image of $1.6-\mu \mathrm{m}$-thick $\mathrm{NiO}$ films on glass slides without treatment (left) and with one TAD cycle (right). Scale bar $=1 \mathrm{~cm}$. (b) Absorbance spectra of $1.6 \mu \mathrm{m}$ films for untreated $\mathrm{NiO}$ (black) and $\mathrm{NiO}$ with one (red), two (green), three (gold), four (blue), and five (violet) cycles of TAD. Inset: Difference spectra determined by subtracting the spectrum of the untreated $\mathrm{NiO}$ film from the spectra of the TAD-treated films. (c) Cyclic voltammetry versus $\mathrm{Ag} / \mathrm{AgCl}$ potential for films of untreated $\mathrm{NiO}$ (green) and single-cycle $\mathrm{TAD}$ treated $\mathrm{NiO}$ (orange) collected with a scan rate of $20 \mathrm{mV} \cdot \mathrm{s}^{-1}$ in acetonitrile with $0.1 \mathrm{M}$ lithium perchlorate. (d) Left: Chemical capacitance and DOS versus $\mathrm{Ag} / \mathrm{AgCl}$ potential for films of untreated $\mathrm{NiO}$ (green) and $\mathrm{NiO}$ treated with one cycle of TAD (orange). Right: Difference spectrum (black line) determined by subtracting the spectra of the TAD-treated films from the spectrum of the untreated $\mathrm{NiO}$ film. The spectrum is well fit to the summation of four Gaussians (dashed lines) centered at $-0.11,0.23,0.82$, and $1.20 \mathrm{~V}$ versus $\mathrm{Ag} / \mathrm{AgCl}$. 
This similarity suggests that the defect states passivated by $\mathrm{TAD}$ are the same defect states that give rise to the well-known electrochromism of the material. ${ }^{14,38}$

Cyclic voltammetry was used to further probe the electronic states that could be responsible for bleaching of the $\mathrm{NiO}$ films by $\mathrm{TAD}$, as shown in Figure $2 \mathrm{c}$. The voltammogram for neat $\mathrm{NiO}$ is not symmetric and shows at least three reversible peaks, which have previously been assigned to trap states slightly above the valence band maximum (VBM) and associated with Ni vacancies. ${ }^{2-24}$ Strikingly, however, these peaks disappear upon one cycle of $\mathrm{TAD}$, as shown by the symmetric voltammogram in Figure 2c. Using the cathodic wave, the data were converted into chemical capacitance and the equivalent density of states (DOS), as shown in Figure $2 \mathrm{~d}$. For neat $\mathrm{NiO}$, the $\mathrm{DOS}$ integrated over the energy range in Figure $2 \mathrm{~d}$ yields a value of $4.3 \times 10^{20} \mathrm{~cm}^{-3}$, which is in good agreement with literature values, assuming a porosity of $50 \%$ for the films. ${ }^{23}$ The $\mathrm{TAD}$-treated $\mathrm{NiO}$ shows a substantially lower DOS and a functional form as expected for a defect-free semiconductor with a valence band edge at $\sim 0.2 \mathrm{~V}$ versus silver/silver chloride $(\mathrm{Ag} / \mathrm{AgCl})$.

The difference spectrum between the DOS for neat and $\mathrm{TAD}$-treated $\mathrm{NiO}$ (right-hand side of Figure $2 \mathrm{~d}$ ) yields the spectrum of the traps passivated by one cycle of TAD, which is well fit to the summation of four Gaussian peaks. Integrating the DOS yields a total trap density of $1.7 \times 10^{20} \mathrm{~cm}^{-3}$. Assuming each defect site is passivated by only one $\mathrm{Al}$, complete passivation of these states would require the equivalent of $\sim 0.1$ monolayers, which is consistent with the submonolayer deposition of the TAD process. These electrochemical results, combined with the low deposition rate and chemical differences between TAD and ALD, suggest that the $\mathrm{TAD}$ process preferentially targets the chemically distinct defect sites of the material and that nearly complete passivation is achieved with only a single cycle.

First-Principles Calculations of Ni Vacancy Defects. We performed first-principles calculations to better understand the origin of TAD passivation at an atomistic level. The $\mathrm{NiO}$ (111) surface was modeled using DFT with the Hubbard correction, ${ }^{39}$ which has previously been used to accurately describe the antiferromagnetic and electronic properties of $\mathrm{NiO}$, as discussed in ref 37 . The Hubbard term is necessary to account for the strong electron correlation from the partially filled $\mathrm{d}$ orbitals on the $\mathrm{Ni}$ atoms. On the basis of our experimental observations, which are insensitive to different surface orientations (see below), we hypothesized that the defect states are most likely to arise from single $\mathrm{Ni}$ vacancies in stoichiometric $\mathrm{NiO}$ layers and that these states would be passivated by the addition of Al. As recently demonstrated, ${ }^{37}$ the (111) surface shows a rich variety of reconstruction phases. Here, we modeled the most stable phase, the octopolar reconstruction, and included an atomic Ni vacancy in the first stoichiometric layer of the surface. As shown by the electron density isosurface in Figure 3a, the calculation confirms that a $\mathrm{Ni}$ vacancy induces a set of localized electronic states, which envelop $\mathrm{O}$ atoms in the layers directly above and below the $\mathrm{Ni}$ vacancy. Qualitatively, these states can be considered to be the $\mathrm{O}$ dangling bonds resulting from the vacancy. The states give rise to a broad set of peaks in the DOS approximately $0.4 \mathrm{eV}$ above the VBM, as shown by the yellow shaded area denoted by green arrows in Figure $3 \mathrm{~b}$. Importantly, the states are localized near the surface and do not extend deeper into the bulk, as is apparent from the layer-resolved DOS in Figure $3 \mathrm{~b}$. a

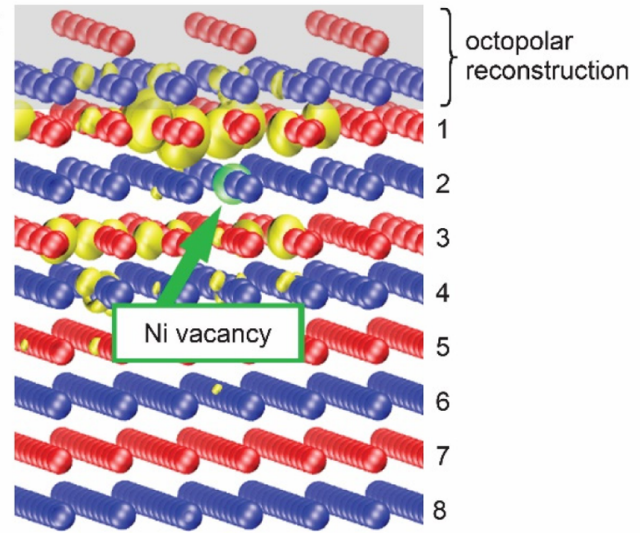

b

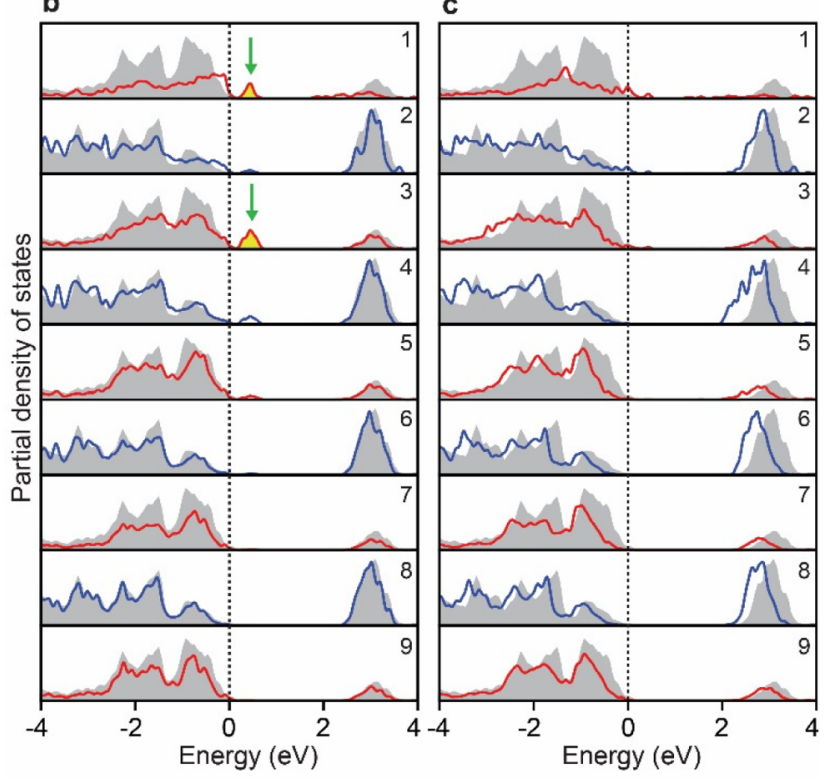

Figure 3. First-principles calculations of defect states and passivation in $\mathrm{NiO}$ : (a) Structure of the octopolar $\mathrm{NiO}$ (111) surface with a single $\mathrm{Ni}$ vacancy at the position denoted by the green arrow and sphere. Shown in yellow is the electron density isosurface for the defect states generated by $\mathrm{O}$ dangling bonds associated with the vacancy. The topmost bilayer is the nonstoichiometric octopolar surface reconstruction. (b and c) Layer-resolved DOS for stoichiometric $\mathrm{NiO}$ layers near the surface showing the results for the vacancy (panel b) and $\mathrm{Al}$ substitution in the vacancy (panel c). Layers are labeled according to the numbers depicted in panel a, with the vacancy located in layer 2 . All energies are referenced to the VBM of bulk $\mathrm{NiO}$, which is depicted with the vertical dashed lines. The DOS for bulk $\mathrm{NiO}$ is shown by the gray shaded area. Green arrows and yellow shaded areas in panel $b$ denote the defect states associated with the vacancy.

To test whether these defect states can be removed with $\mathrm{Al}$, we performed a second calculation with an $\mathrm{Al}$ atom filling the vacancy. As is apparent from the DOS in Figure 3c, the broad peaks above the VBM disappear. Qualitatively, the $\mathrm{Al}$ atom can be considered to passivate the $\mathrm{O}$ dangling bonds created by the vacancy. The first-principles calculations are in good agreement with experimental measurements in Figure 2, reproducing both the presence of defects above the VBM and passivation with Al. Thus, based on the combination of experimental and firstprinciples results, we attribute the experimentally observed bleaching of $\mathrm{NiO}$ films and elimination of defect states upon $\mathrm{TAD}$ treatment to the selective passivation of the $\mathrm{O}$ dangling bonds associated with $\mathrm{Ni}$ vacancies. 
a

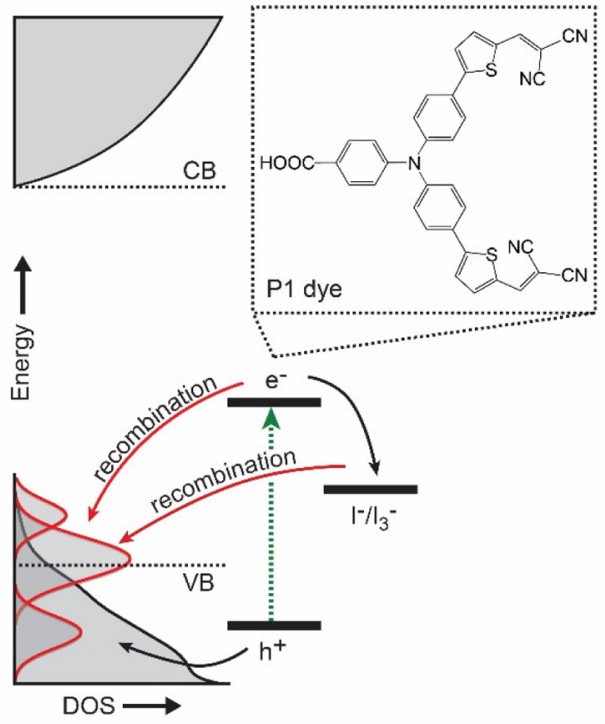

c

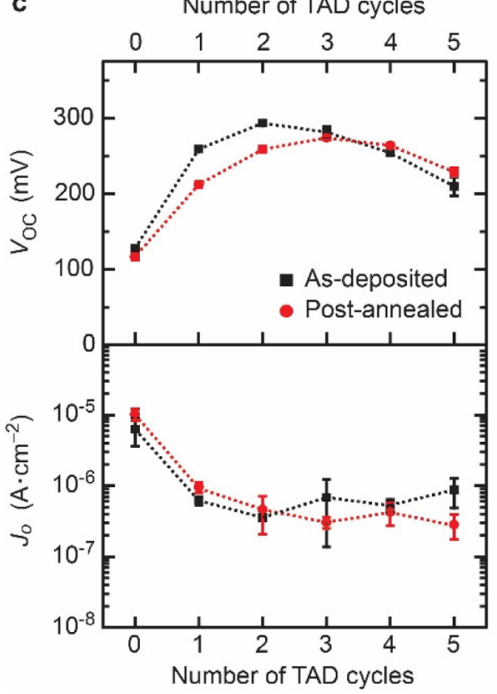

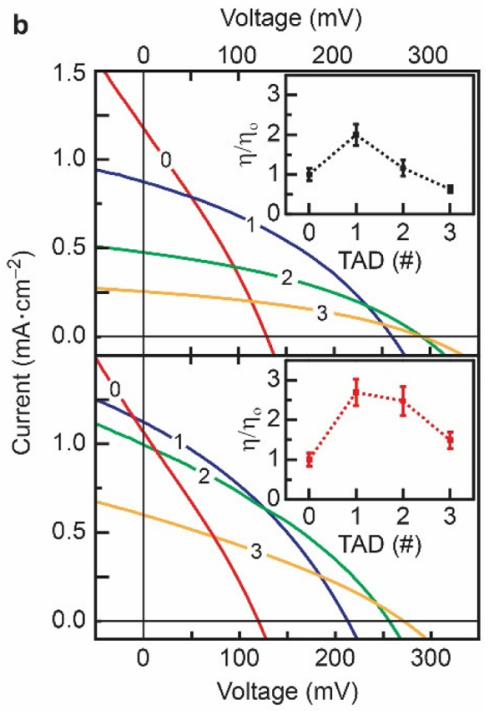

d

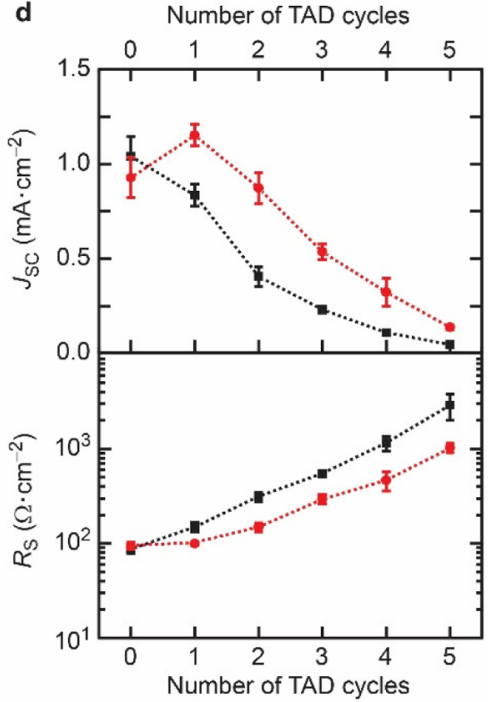

Figure 4. Effect of TAD passivation on a p-type DSSC performance: (a) Energy-level schematic (not to scale) for a p-type DSSC utilizing the P1 dye and $\mathrm{I}^{-} / \mathrm{I}_{3}{ }^{-}$electrolyte. The dashed green arrow represents light absorption by $\mathrm{P} 1$. The passivated surface states associated with recombination are shown as red curves, recombination processes as red arrows, and electron $\left(\mathrm{e}^{-}\right)$and hole $\left(\mathrm{h}^{+}\right)$transfer events as black arrows. (b) Champion $J-V$ curves under 1 sun illumination for zero (red), one (blue), two (green), and three (orange) cycles of TAD for as-deposited (upper) and $450{ }^{\circ} \mathrm{C}$ postannealed (lower) samples. Inset: $\eta$ for each curve relative to $\eta_{0}$, the efficiency of the untreated, zero-cycle sample. (c) Dependence of $V_{\mathrm{OC}}$ (upper) and $J_{0}$ (lower) on the number of TAD cycles for as-deposited (black squares) and postannealed (red circles) samples. (d) Dependence of $J_{\mathrm{SC}}$ (upper) and $R_{\mathrm{S}}$ (lower) on the number of TAD cycles for as-deposited (black squares) and postannealed (red circles) samples. Error bars in panels $b-d$ represent standard deviations from sample sizes of $\geq 3$ and were omitted if comparable in size to the marker symbols.

Performance of TAD-Treated DSSCs. The passivation of defects in $\mathrm{NiO}$ should lead to substantial improvements in the performance of solar energy devices by reducing or eliminating charge-carrier recombination facilitated by the defect levels as well as removing trap-state shunt pathways. Below, we characterize the improvement in p-type DSSC devices using the iodide/triodide electrolyte and the P1 organic dye (see the inset in Figure 4a), a well-studied hole-injecting chromophore. $^{27,29,40-44}$ As depicted in Figure 4a, these DSSC devices operate by first injecting holes from $\mathrm{P} 1$ into the $\mathrm{NiO}$ valence band and second regenerating neutral $\mathrm{P} 1$ by electron transfer to the electrolyte.

TAD-treated films of the $\mathrm{NiO}$ nanoplatelets of $\sim 1.6 \mu \mathrm{m}$ thickness were dye-loaded with $\mathrm{P} 1$ and exhibited a vibrant red color (Figure S6), which confirms that the TAD treatment had no appreciable impact on the dye loading or light-harvesting efficiency (LHE) of the films (Figure S7). NiO electrodes with an area of $\sim 0.7 \mathrm{~cm}^{2}$, which is $2-3$-fold larger than previous literature reports with the P1 chromophore, , $27,29,40-44^{\text {were }}$ used to minimize the effect of the electrode size on the measured photovoltaic performance metrics. We fabricated DSSC devices with zero to five cycles of TAD and with and without a postanneal at $450{ }^{\circ} \mathrm{C}$ prior to dye loading (see Tables S3-S6 for all photovoltaic device metrics). Current density versus voltage $(J-V)$ curves under simulated 1 sun illumination are shown in Figure 4b. Most notable in the $J-V$ curves is the dramatic increase in the open-circuit voltage $\left(V_{\text {OC }}\right)$ from 129 $\mathrm{mV}$ for neat $\mathrm{NiO}$ to a maximum of $294 \mathrm{mV}$ for two cycles of TAD without a postanneal. This upper value is close to the theoretical limit of $\sim 300 \mathrm{mV}$, as given by the difference 
between the valence band edge of $\mathrm{NiO}$ and the Nernstian potential of the electrolyte. IPCE measurements were performed to confirm that photocurrent production was from dye sensitization (Figure S7). We also fabricated devices using commercial $\mathrm{NiO}$ nanoparticles and observed the same improvement (Figure S8), which indicates that the results are generic and applicable to $\mathrm{NiO}$ produced by a range of synthetic methods and with a variety of crystallographic orientations.

Analysis of the DSSC Device Performance. The trends in photovoltaic device parameters, including $V_{\mathrm{OC}}$, dark saturation current density $\left(J_{0}\right)$, short-circuit current density $\left(J_{\mathrm{SC}}\right)$, and series resistance $\left(R_{\mathrm{S}}\right)$ as a function of the number of TAD cycles, are shown in Figure $4 c, d$ and reveal two important aspects of the devices fabricated without a postanneal (black curves). First, $V_{\mathrm{OC}}$ exhibits a maximum at two cycles but then plateaus and begins to fall at four to five cycles. The increase in $V_{\mathrm{OC}}$ within the first two cycles corresponds well with a $1-2$ order of magnitude decrease in $J_{0}$, which then plateaus for higher cycle numbers. The decrease in $J_{0}$ is well correlated with a 1-3 order of magnitude increase in the recombination lifetime of holes in $\mathrm{NiO}$ (Figure S9). Second, $J_{\mathrm{SC}}$ progressively decreases with the increasing number of TAD cycles, following an approximately exponential decay with the cycle number. The changes in $J_{\mathrm{SC}}$ are well-correlated with an increase in $R_{\mathrm{S}}$ (Figure S10), which exhibits an exponential increase with the cycle number. $^{41}$

We attribute the improvement in $V_{\mathrm{OC}}$ at one to two TAD cycles to a reduction in the recombination rate as a result of defect passivation. The drop in $V_{\mathrm{OC}}$ at four to five cycles is likely a result of the low $J_{S C}$ for high cycle numbers, which reduces $V_{\mathrm{OC}}$ because of a decrease in the ratio of $J_{\mathrm{SC}}$ to $J_{0}$, as predicted by the ideal diode equation. In addition, the exponential decrease of $J_{S C}$ with the cycle number is attributed to a decrease in the internal quantum efficiency (IQE) of the devices because the LHE (Figure S7) of the films is constant and $J_{\mathrm{SC}}$ is proportional to the product of IQE and LHE. We hypothesize that the decrease in IQE is primarily caused by a lowered charge-injection efficiency from $\mathrm{P} 1$ into the $\mathrm{NiO}$ valence band as a result of tunneling through additional $\mathrm{AlO}_{x}$ or $\mathrm{Al}(\mathrm{OH})_{x}$ insulating layers. An exponential dependence of the rate of charge injection on the layer thickness is a well-known effect for ALD deposition of insulating shells on metal oxide nanomaterials. ${ }^{45}$ The decrease in IQE may also partially result from the reduced efficiency for charge transport through the film, manifested as an increase in $R_{\mathrm{S}}$ that causes a deleterious increase in charge-carrier recombination.

For the first two TAD cycles, the postanneal at $450{ }^{\circ} \mathrm{C}$ on average reduces $V_{\mathrm{OC}}$ and $R_{\mathrm{S}}$ by $12 \%$ and $52 \%$ and increases $J_{0}$ and $J_{S C}$ by $5 \%$ and $40 \%$, respectively, as is apparent from the difference between the black and red curves in Figure 4c,d. For all cycles, the change in $V_{\mathrm{OC}}$ relative to the nonannealed sample is well correlated with the change in $J_{0}$, and similarly the increase in $J_{\mathrm{SC}}$ for the postannealed samples compared to the nonannealed samples is correlated with the lower $R_{\mathrm{S}}$. XPS spectra collected on the annealed samples (Figures S4 and S11) indicate that the anneal converts $\mathrm{Al}(\mathrm{OH})_{x}$ to $\mathrm{AlO}_{x}$. This result suggests that the oxide species produced by the postannealing treatment improves the efficiency of charge transfer at the surfaces and interfaces compared to the hydroxide species in nonannealed samples, producing the trade-off of a beneficial decrease in $R_{\mathrm{S}}$ and a detrimental increase in $J_{0}$ upon the postanneal. In addition, it is possible that the anneal drives $\mathrm{Al}$ into the interior of the particles, passivating bulk defects, but an additional investigation would be necessary to confirm this hypothesis. Interestingly, the postannealed sample with one cycle of TAD exhibits the highest 1 sun power conversion $(\eta)$ across all devices because the increase in $J_{\mathrm{SC}}$ upon annealing more than compensates for the relatively small loss in $V_{\mathrm{OC}}$ (see the inset in Figure $4 b$ ).

We also fabricated DSSC devices from $\mathrm{NiO}$ treated with a single deposition cycle at $200{ }^{\circ} \mathrm{C}$ (Figure S12 and Table S7). These devices exhibited a maximum $V_{\mathrm{OC}}$ of $135 \mathrm{mV}$ and a maximum $J_{\mathrm{SC}}$ of $0.038 \mathrm{~mA} \cdot \mathrm{cm}^{-2}$. If we assume the $200{ }^{\circ} \mathrm{C}$ single-cycle deposition is similar to an ALD cycle and produces a monolayer of $\mathrm{AlO}_{x}$ coverage, the $97 \%$ decrease in $J_{\mathrm{SC}}$ compared to untreated $\mathrm{NiO}$ can be explained by a more than $50 \%$ drop in the rate of electron transfer from $\mathrm{P} 1$ as a result of an $\sim 1.5$ - $\AA$-thick tunneling barrier with a barrier height of $\sim 1.6$ $\mathrm{eV}^{45}$ The poor photovoltaic performance following this ALD treatment highlights the importance of the site-selective passivation provided by $\mathrm{TAD}$ to improve the photovoltaic properties of nanomaterials without detrimentally altering their fundamental performance characteristics.

\section{CONCLUSIONS}

Here, we have shown that the TAD process, which uses a vapor-phase precursor to selectively passivate the chemically distinct defect sites in nanomaterials, can dramatically improve the DSSC performance of the ubiquitous solar photocathode material $\mathrm{NiO}$. We expect that this result will easily be translated to improvements in other solar-energy devices incorporating $\mathrm{NiO}$, including organic photovoltaics ${ }^{17}$ and organohalide perovskites. ${ }^{18}$ In addition, we believe that the TAD process can be developed with a broad range of vapor-phase precursors and could represent a general strategy to passivate defects sites in $0 \mathrm{D}, 1 \mathrm{D}$, and $2 \mathrm{D}$ nanomaterials.

\section{ASSOCIATED CONTENT}

\section{S Supporting Information}

The Supporting Information is available free of charge on the ACS Publications website at DOI: 10.1021/acsami.6b01090.

EDS mapping of TAD- and ALD-treated NiO nanoplatelets (Figures S1 and S2), XPS data on untreated and TAD-treated $\mathrm{NiO}$ as a function of the deposition temperature and number of cycles (Figures S3, S4, and S11), spectroelectrochemical data (Figure S5), optical images, UV-vis spectroscopy, and IPCE measurements (Figures S6 and S7), additional photovoltaic device data (Figures S8-S10 and S12), quantitative determination of the $\mathrm{Al}$ content (Tables $\mathrm{S} 1$ and S2), additional photovoltaic device data (Tables S3-S7), TAD deposition conditions (Tables S8 and S9), extended discussion section of XPS spectra, and details of the theoretical method (PDF)

\section{AUTHOR INFORMATION}

\section{Corresponding Author}

*E-mail: jfcahoon@unc.edu.

\section{Author Contributions}

C.J.F. and J.F.C. conceived and designed the experiments and wrote the manuscript. S.M.M., E.O., C.C.M., and B.H.F. assisted with experimental measurements. C.L.D. performed XPS measurements and interpretation, and J.R.M. collected the STEM images. W.L. and W.Y. synthesized the P1 chromophore. L.L. and Y.K. performed first-principles calculations. All 
authors commented on the manuscript and assisted in the analysis and interpretation of the data.

\section{Notes}

The authors declare no competing financial interest.

\section{ACKNOWLEDGMENTS}

This work was primarily funded by the University of North Carolina, Energy Frontier Research Center (EFRC), "Center for Solar Fuels", funded by the U.S. Department of Energy, Office of Science, Office of Basic Energy Sciences, under Award DE-SC0001011. J.F.C. acknowledges a Packard Fellowship for Science and Engineering. J.R.M. acknowledges NSF support from Grants CHE-1213758 and EPS-1004083. We also acknowledge the use of specialized equipment supported by the National Science Foundation (Grant DMR-1308695). The authors acknowledge $\mathrm{R}$. White for assistance with device fabrication, T. Celano for 3D graphics, and G. Meyer for fruitful discussions.

\section{REFERENCES}

(1) Reetz, M. T.; Westermann, E. Phosphane-Free PalladiumCatalyzed Coupling Reactions: The Decisive Role of Pd Nanoparticles. Angew. Chem., Int. Ed. 2000, 39 (1), 165-168.

(2) O’Regan, B.; Gratzel, M. A Low-Cost, High-Efficiency Solar Cell based on Dye-Sensitized Colloidal $\mathrm{TiO}_{2}$ Films. Nature 1991, 353 (6346), 737-740.

(3) Zheng, G.; Lee, S. W.; Liang, Z.; Lee, H.-W.; Yan, K.; Yao, H.; Wang, H.; Li, W.; Chu, S.; Cui, Y. Interconnected Hollow Carbon Nanospheres for Stable Lithium Metal Anodes. Nat. Nanotechnol. 2014, 9 (8), 618-623.

(4) Liu, J.; Lu, Y. Fast Colorimetric Sensing of Adenosine and Cocaine based on a General Sensor Design involving Aptamers and Nanoparticles. Angew. Chem., Int. Ed. 2006, 45 (1), 90-94.

(5) Hines, D. A.; Kamat, P. V. Recent Advances in Quantum Dot Surface Chemistry. ACS Appl. Mater. Interfaces 2014, 6 (5), 30413057.

(6) Lee, J.-S.; Kovalenko, M. V.; Huang, J.; Chung, D. S.; Talapin, D. V. Band-like Transport, High Electron Mobility and High Photoconductivity in All-Inorganic Nanocrystal Arrays. Nat. Nanotechnol. 2011, 6 (6), 348-352.

(7) Nozik, A. J. Quantum dot solar cells. Phys. E 2002, 14 (1-2), 115-120.

(8) Kamat, P. V. Quantum Dot Solar Cells. Semiconductor Nanocrystals as Light Harvesters. J. Phys. Chem. C 2008, 112 (48), 18737-18753.

(9) Mariani, G.; Scofield, A. C.; Hung, C.-H.; Huffaker, D. L. GaAs Nanopillar-Array Solar Cells Employing in situ Surface Passivation. Nat. Commun. 2013, 4, 1497.

(10) McDonnell, S.; Addou, R.; Buie, C.; Wallace, R. M.; Hinkle, C. L. Defect-Dominated Doping and Contact Resistance in $\mathrm{MoS}_{2}$. ACS Nano 2014, 8 (3), 2880-2888.

(11) Hwang, J.-Y.; Kuo, C.-C.; Chen, L.-C; Chen, K-H. Correlating Defect Density with Carrier Mobility in Large-Scaled Graphene Films: Raman Spectral Signatures for the Estimation of Defect Density. Nanotechnology 2010, 21 (46), 465705.

(12) Kim, K.; Lee, H.-B.-R.; Johnson, R. W.; Tanskanen, J. T.; Liu, N.; Kim, M.-G.; Pang, C.; Ahn, C.; Bent, S. F.; Bao, Z. Selective Metal Deposition at Graphene Line Defects by Atomic Layer Deposition. Nat. Commun. 2014, 5, 4781.

(13) Guijarro, N.; Prevot, M. S.; Sivula, K. Surface Modification of Semiconductor Photoelectrodes. Phys. Chem. Chem. Phys. 2015, 17 (24), 15655-15674.

(14) Svensson, J. S. E. M.; Granqvist, C. G. Electrochromic Hydrated Nickel Oxide Coatings for Energy Efficient Windows: Optical Properties and Coloration Mechanism. Appl. Phys. Lett. 1986, 49 (23), 1566-1568.
(15) Yuan, Y. F.; Xia, X. H.; Wu, J. B.; Yang, J. L.; Chen, Y. B.; Guo, S. Y. Hierarchically Ordered Porous Nickel Oxide Array Film with Enhanced Electrochemical Properties for Lithium Ion Batteries. Electrochem. Commun. 2010, 12 (7), 890-893.

(16) Fominykh, K.; Chernev, P.; Zaharieva, I.; Sicklinger, J.; Stefanic, G.; Döblinger, M.; Müller, A.; Pokharel, A.; Böcklein, S.; Scheu, C.; Bein, T.; Fattakhova-Rohlfing, D. Iron-Doped Nickel Oxide Nanocrystals as Highly Efficient Electrocatalysts for Alkaline Water Splitting. ACS Nano 2015, 9 (5), 5180-5188.

(17) Manders, J. R.; Tsang, S.-W.; Hartel, M. J.; Lai, T.-H.; Chen, S.; Amb, C. M.; Reynolds, J. R.; So, F. Solution-Processed Nickel Oxide Hole Transport Layers in High Efficiency Polymer Photovoltaic Cells. Adv. Funct. Mater. 2013, 23 (23), 2993-3001.

(18) Wang, K.-C.; Jeng, J.-Y.; Shen, P.-S.; Chang, Y.-C.; Diau, E. W.G.; Tsai, C.-H.; Chao, T.-Y.; Hsu, H.-C.; Lin, P.-Y.; Chen, P.; Guo, T.F.; Wen, T.-C. P-Type mesoscopic Nickel Oxide/Organometallic Perovskite Heterojunction Solar Cells. Sci. Rep. 2014, 4, 4756.

(19) Flynn, C. J.; Oh, E. E.; McCullough, S. M.; Call, R. W.; Donley, C. L.; Lopez, R.; Cahoon, J. F. Hierarchically-Structured NiO Nanoplatelets as Mesoscale p-Type Photocathodes for Dye-Sensitized Solar Cells. J. Phys. Chem. C 2014, 118 (26), 14177-14184.

(20) Perera, I. R.; Daeneke, T.; Makuta, S.; Yu, Z.; Tachibana, Y.; Mishra, A.; Bäuerle, P.; Ohlin, C. A.; Bach, U.; Spiccia, L. Application of the tris(acetylacetonato)Iron(III)/(II) Redox Couple in p-Type Dye-Sensitized Solar Cells. Angew. Chem., Int. Ed. 2015, 54 (12), 3758-3762.

(21) Nattestad, A.; Mozer, A. J.; Fischer, M. K. R.; Cheng, Y. B.; Mishra, A.; Bauerle, P.; Bach, U. Highly Efficient Photocathodes for Dye-Sensitized Tandem Solar Cells. Nat. Mater. 2010, 9 (1), 31-35.

(22) Zhu, H.; Hagfeldt, A.; Boschloo, G. Photoelectrochemistry of Mesoporous $\mathrm{NiO}$ Electrodes in Iodide/Triiodide Electrolytes. J. Phys. Chem. C 2007, 111 (47), 17455-17458.

(23) D’Amario, L.; Boschloo, G.; Hagfeldt, A.; Hammarström, L. Tuning of Conductivity and Density of States of $\mathrm{NiO}$ Mesoporous Films used in p-Type DSSCs. J. Phys. Chem. C 2014, 118 (34), 19556-19564.

(24) D’Amario, L.; Antila, L. J.; Pettersson Rimgard, B.; Boschloo, G.; Hammarström, L. Kinetic Evidence of Two Pathways for Charge Recombination in NiO-based Dye-Sensitized Solar Cells. J. Phys. Chem. Lett. 2015, 6 (5), 779-783.

(25) Odobel, F.; Pellegrin, Y.; Gibson, E. A.; Hagfeldt, A.; Smeigh, A. L.; Hammarström, L. Recent Advances and Future Directions to Optimize the Performances of p-Type Dye-Sensitized Solar Cells. Coord. Chem. Rev. 2012, 256 (21-22), 2414-2423.

(26) Zhang, X. L.; Huang, F.; Nattestad, A.; Wang, K.; Fu, D.; Mishra, A.; Bauerle, P.; Bach, U.; Cheng, Y.-B. Enhanced Open-Circuit Voltage of p-Type DSC with Highly Crystalline NiO Nanoparticles. Chem. Commun. 2011, 47 (16), 4808-4810.

(27) Gibson, E. A.; Awais, M.; Dini, D.; Dowling, D. P.; Pryce, M. T.; Vos, J. G.; Boschloo, G.; Hagfeldt, A. Dye Sensitised Solar Cells with Nickel Oxide Photocathodes Prepared via Scalable Microwave Sintering. Phys. Chem. Chem. Phys. 2013, 15 (7), 2411-2420.

(28) Zhang, X. L.; Zhang, Z.; Chen, D.; Bauerle, P.; Bach, U.; Cheng, Y.-B. Sensitization of Nickel Oxide: Improved Carrier Lifetime and Charge Collection by Tuning Nanoscale Crystallinity. Chem. Commun. 2012, 48 (79), 9885-9887.

(29) Natu, G.; Huang, Z.; Ji, Z.; Wu, Y. The Effect of an Atomically Deposited Layer of Alumina on $\mathrm{NiO}$ in p-Type Dye-Sensitized Solar Cells. Langmuir 2012, 28 (1), 950-956.

(30) Uehara, S.; Sumikura, S.; Suzuki, E.; Mori, S. Retardation of Electron Injection at $\mathrm{NiO} / \mathrm{Dye} /$ Electrolyte Interface by Aluminium Alkoxide Treatment. Energy Environ. Sci. 2010, 3 (5), 641-644.

(31) Leskelä, M.; Ritala, M. Atomic Layer Deposition Chemistry: Recent Developments and Future Challenges. Angew. Chem., Int. Ed. 2003, 42 (45), 5548-5554.

(32) Päiväsaari, J.; Putkonen, M.; Sajavaara, T.; Niinistö, L. Atomic Layer Deposition of Rare Earth Oxides: Erbium Oxide Thin Films from $\beta$-diketonate and Ozone Precursors. J. Alloys Compd. 2004, 374 $(1-2), 124-128$. 
(33) Lim, J.; Lee, C. Effects of Substrate temperature on the Microstructure and Photoluminescence Properties of $\mathrm{ZnO}$ Thin Films Prepared by Atomic Layer Deposition. Thin Solid Films 2007, 515 (78), 3335-3338.

(34) Lie, M.; Fjellvåg, H.; Kjekshus, A. Growth of $\mathrm{Fe}_{2} \mathrm{O}_{3}$ Thin Films by Atomic Layer Deposition. Thin Solid Films 2005, 488 (1-2), 7481.

(35) Cassir, M.; Goubin, F.; Bernay, C.; Vernoux, P.; Lincot, D. Synthesis of $\mathrm{ZrO}_{2}$ Thin Films by Atomic Layer Deposition: Growth Kinetics, Structural and Electrical Properties. Appl. Surf. Sci. 2002, 193 (1-4), 120-128.

(36) Ito, S.; Murakami, T. N.; Comte, P.; Liska, P.; Grätzel, C.; Nazeeruddin, M. K.; Grätzel, M. Fabrication of Thin Film Dye Sensitized Solar Cells with Solar to Electric Power Conversion Efficiency over 10\%. Thin Solid Films 2008, 516 (14), 4613-4619.

(37) Li, L.; Kanai, Y. Antiferromagnetic Structures and Electronic Energy Levels at Reconstructed $\mathrm{NiO}(111)$ Surfaces: A DFT+U Study. Phys. Rev. B: Condens. Matter Mater. Phys. 2015, 91 (23), 235304.

(38) Wen, R.-T.; Granqvist, C. G.; Niklasson, G. A. Anodic Electrochromism for Energy-Efficient Windows: Cation/Anion-Based Surface Processes and Effects of Crystal Facets in Nickel Oxide Thin Films. Adv. Funct. Mater. 2015, 25 (22), 3359-3370.

(39) Kulik, H. J. Perspective: Treating Electron Over-Delocalization with the DFT+U Method. J. Chem. Phys. 2015, 142 (24), 240901.

(40) Li, L.; Gibson, E. A.; Qin, P.; Boschloo, G.; Gorlov, M.; Hagfeldt, A.; Sun, L. Double-Layered NiO Photocathodes for p-Type DSSCs with Record IPCE. Adv. Mater. 2010, 22 (15), 1759-1762.

(41) Huang, Z.; Natu, G.; Ji, Z.; Hasin, P.; Wu, Y. P-Type DyeSensitized NiO Solar Cells: A Study by Electrochemical Impedance Spectroscopy. J. Phys. Chem. C 2011, 115 (50), 25109-25114.

(42) Qin, P.; Zhu, H.; Edvinsson, T.; Boschloo, G.; Hagfeldt, A.; Sun, L. Design of an Organic Chromophore for p-Type Dye-Sensitized Solar Cells. J. Am. Chem. Soc. 2008, 130 (27), 8570-8571.

(43) Qin, P.; Linder, M.; Brinck, T.; Boschloo, G.; Hagfeldt, A.; Sun, L. High Incident Photon-to-Current Conversion Efficiency of p-Type Dye-Sensitized Solar Cells based on $\mathrm{NiO}$ and Organic Chromophores. Adv. Mater. 2009, 21 (29), 2993-2996.

(44) Zannotti, M.; Wood, C. J.; Summers, G. H.; Stevens, L. A.; Hall, M. R.; Snape, C. E.; Giovanetti, R.; Gibson, E. A. Ni Mg Mixed Metal Oxides for p-Type Dye-Sensitized Solar Cells. ACS Appl. Mater. Interfaces 2015, 7 (44), 24556-24565.

(45) Prasittichai, C.; Avila, J. R.; Farha, O. K.; Hupp, J. T. Systematic Modulation of Quantum (Electron) Tunneling Behavior by Atomic Layer Deposition on Nanoparticulate $\mathrm{SnO}_{2}$ and $\mathrm{TiO}_{2}$ Photoanodes. J. Am. Chem. Soc. 2013, 135 (44), 16328-16331. 